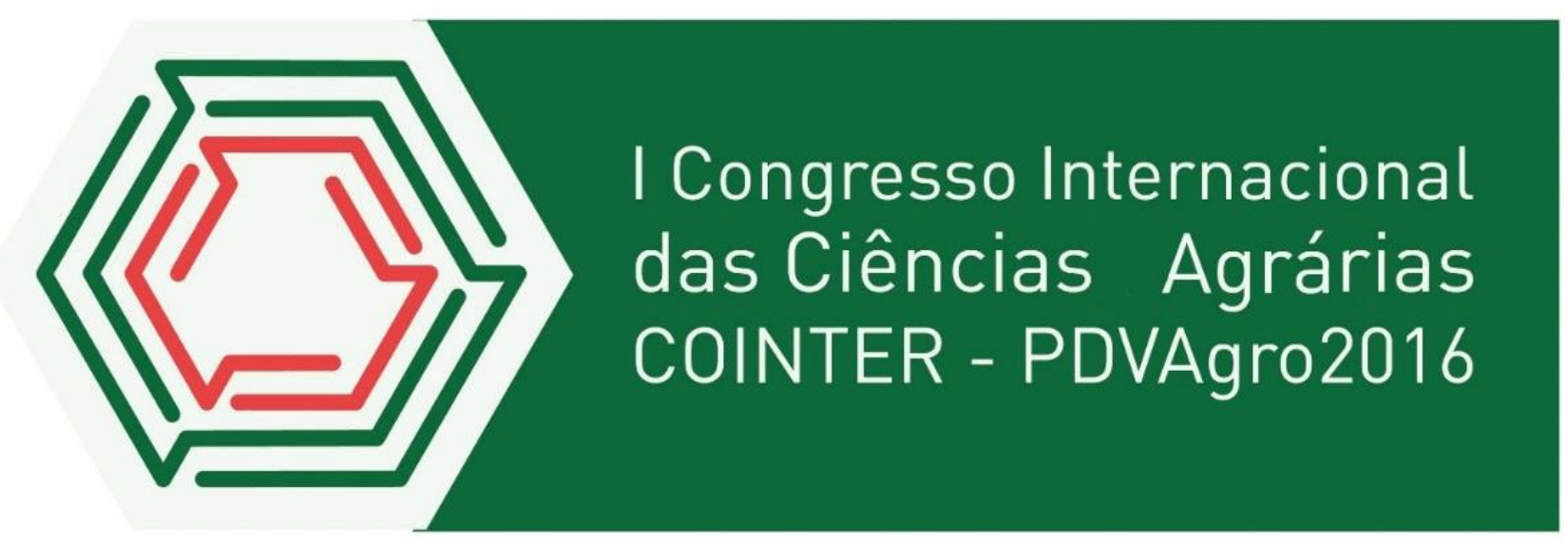

\title{
ESTRATÉGIAS DE DESENVOLVIMENTO TERRITORIAL: O CASO DOS GRUPOS TEMÁTICOS DO TERRITÓRIO PIEMONTE DA BORBOREMA
}

\author{
Apresentação: Comunicação Oral \\ MSc. Tarciso Botelho Pereira Filho ${ }^{1}$; MSc. Rute Vieira ${ }^{2}$; Priscila Sousa Pereira ${ }^{3}$, Dr $^{\text {a }}$ Amanda \\ Christinne Nascimento Marques ${ }^{4}$; Dr. Fillipe Silveira Marini ${ }^{5}$
}

\section{Resumo}

As diferentes experiências de desenvolvimento territorial no Brasil apontam a necessidade de organização e pactuação da sociedade em torno de objetivos comuns e de que essas condições podem ser construídas. Nesse momento, se amplia a participação da sociedade civil organizada nos processos de tomada de decisão. O Território Piemonte da Borborema, homologado em 2010, é formado por entidades da sociedade civil e poder público em 20 municípios, em que são construídas ações destinadas especialmente aos agricultores familiares, mulheres camponesas, assentados, povos quilombolas e juventude rural. Esse Território é formado pelo Colegiado Territorial, Núcleo Dirigente, Grupos Temáticos (Câmaras e os Comitês Setoriais) e pelo Núcleo Técnico. A instância máxima é o Colegiado Territorial, no entanto, este busca ocupar os espaços políticos e apresentar propostas de políticas públicas por meio da constituição dos grupos temáticos. O objeto de estudo desse artigo são os grupos temáticos existentes no Território Piemonte da Borborema, os quais são formados de acordo com os grupos identitários que se reúnem para além do Plenário do Colegiado e articulam segmentos ou grupos sociais diversos dentro do Território. Partindo desse desígnio, este trabalho objetiva analisar e discutir a dinâmica do desenvolvimento no Território Rural Piemonte da Borborema por meio do funcionamento dos grupos temáticos existentes: Comitê de Gênero, Comitê de Povos e Populações Tradicionais, Comitê de Juventude Rural e Câmara de Inclusão Produtiva, de maneira a verificar as relações entre o seu ideário e as consequências práticas de sua atuação. $\mathrm{O}$ estudo foi realizado a partir da abordagem qualitativa, associado ao levantamento bibliográfico em que foi utilizada a coleta de dados secundários. A pesquisa teve como intuito contribuir para o enriquecimento do tema abordado e fomentar o desenvolvimento territorial a partir do fortalecimento dos Grupos de Trabalhos do Território. O estudo revelou que apesar do pouco tempo de criação desses grupos, foram realizadas reuniões de formação política, empoderamento dos sujeitos, participação de encontros em outros territórios, formação e redescobrimento da identidade territorial bem como fortalecimentos das relações interpessoais. Apesar de serem grupos formados por identidades distintas, existem condições especiais que os unem, sendo possível perceber quilombolas e jovens

\footnotetext{
${ }^{1}$ Mestre em Ciências Agrárias (Agroecologia), Centro de Ciências Humanas, Sociais e Agrárias (CCHSA)/Universidade Federal da Paraíba (UFPB), tarcisobotelho@live.com

${ }^{2}$ Mestre em Geografia, CCEN /UFPB, rutgeoufpb@gmail.com

${ }^{3}$ Graduanda em Ciências Agrárias, CCHSA/UFPB, priscilasousa.net@hotmail.com

${ }^{4}$ Professora Doutora em Geografia, CCHSA/UFPB, amandamarques.geografia@gmail.com

${ }^{5}$ Professor Doutor em Produção Vegetal, CCEN/UFPB, fsmarini@yahoo.com.br
} 
participando do Comitê de Mulheres e vice-versa. Concluiu-se que o Comitê de Gênero, Comitê de Povos e Populações Tradicionais, Comitê de Juventude Rural e Câmara de Inclusão Produtiva vem favorecendo a dinâmica do desenvolvimento territorial a partir do empoderamento político e cultural dos sujeitos pertencentes a estes grupos específicos.

Palavras-Chave: Política territorial, Comitê Setorial, Juventude Rural, Gênero.

\section{Introdução}

Nos anos 1980 e 1990 profundas transformações ocorreram no Brasil. A constituição brasileira de 1988 redefiniu o papel e o caráter do Estado nas políticas de descentralização com o pressuposto de transferência de responsabilidades no processo de implementação das políticas públicas, do governo federal para os governos estaduais e municipais.

Considerando que a descentralização das políticas públicas voltadas para a promoção do desenvolvimento rural sustentável não atendeu as especificidades e as diferenças culturais dos vários grupos e povos existentes, no ano de 2003, o governo federal, por meio da então Secretaria de Desenvolvimento Territorial (SDT), do extinto Ministério de Desenvolvimento Agrário (MDA), iniciou uma política de "promoção de desenvolvimento dos territórios rurais", considerando que esses são "espaços de integração, articulação e concentração da diversidade de atores sociais, identidades culturais, interesses políticos e políticas públicas que nele se manifestam” (BRASIL, 2005a). Nesse mesmo ano iniciou-se a execução dessa política cujas ações estão ligadas ao Programa Nacional de Apoio aos Territórios Rurais - PRONAT.

A concepção de território utilizada nesse trabalho dialoga com a do Ministério do Desenvolvimento Agrário-MDA, que entende território como "espaço físico, geograficamente definido, não necessariamente contínuo, compreendendo cidades e campos, caracterizado por critérios multidimensionais, tais como o ambiente, a economia, a sociedade, a cultura, a política e as instituições e uma população com grupos sociais relativamente distintos, que se relacionam interna e externamente por meio de processos específicos, onde se pode distinguir um ou mais elementos que indicam identidade e coesão social, cultural e territorial"(BRASIL, 2005).

No Brasil, em 2010, de acordo com o MDA, foram definidos 164 territórios. No estado da Paraíba existem 15 Territórios. O objeto de estudo desse trabalho é analisar o Território Piemonte da Borborema, o qual foi homologado em 2010 e reconhecido pelo CONDRAF apenas em 2013. O Território Piemonte da Borborema é formado por 20 municípios e congregam entidades da sociedade civil e poder público em torno da construção de ações destinadas, em especial, aos agricultores familiares, mulheres camponesas, assentados, povos quilombolas e juventude rural.

O referido território é formado pelas instâncias: Colegiados Territoriais, que se reúnem para tomar decisões em Plenário; Núcleo Dirigente chamado de Coordenação Executiva, por Grupos 
Temáticos que são as Câmaras e os Comitês Setoriais e pelo Núcleo Técnico. A abordagem territorial tem na equidade, no respeito à diversidade, à solidariedade, à justiça social, no sentimento de pertencimento cultural e na inclusão social, metas fundamentais a serem atingidas e conquistadas por todas essas instâncias.

Dentro dessas estruturas, os comitês setoriais se reúnem mensalmente e mantém articulação mais próxima das demandas do Território. Sua grande importância dar-se por serem grupos temáticos criados para além do Plenário do Colegiado Territorial com vistas à condução de atividades, bem como acompanhar e articular ações e políticas públicas direcionadas para grupos sociais específicos. Com funções específicas das atividades setoriais em cada uma das áreas definidas, os comitês desempenham importante papel na interlocução em suas áreas de competências.

Partindo desse pressuposto, este trabalho tem o objetivo de analisar e discutir a dinâmica do desenvolvimento no Território Rural Piemonte da Borborema, por meio do funcionamento dos grupos temáticos existentes: Comitê de Gênero, Comitê de Povos e Populações Tradicionais, Comitê de Juventude Rural e Câmara de Inclusão Produtiva, de maneira a verificar as relações entre o seu ideário e as consequências práticas de sua atuação.

O estudo foi realizado a partir da abordagem qualitativa, associado ao levantamento bibliográfico em que foi utilizada a coleta de dados secundários. A pesquisa teve como intuito contribuir para o enriquecimento do tema abordado e fomentar o desenvolvimento territorial a partir do fortalecimento dos Grupos de Trabalhos do Território Piemonte da Borborema.

\section{Fundamentação Teórica}

Segundo Veiga (1998), desenvolvimento é um processo sistêmico mediante o qual uma economia consegue simultaneamente crescer, reduzir desigualdades sociais e preservar o meio ambiente. Para Gehlen (2004), a ideia de desenvolvimento está diretamente vinculada às políticas públicas e suas relações com as organizações.

As concepções de desenvolvimento vêm concebendo uma nova disposição nas políticas públicas. Trata-se da tendência de deslocar o objeto das políticas da perspectiva setorial para a perspectiva integradora. Transição que vem refletindo-se nos instrumentos de gestão e planejamento do desenvolvimento rural, como é possível apreender nas políticas públicas protagonistas das últimas décadas no Brasil.

O que vemos é o redescobrimento do território enquanto categoria política adequada para nortear as estratégias de políticas públicas. Para efeito desta pesquisa, entende-se o território como o espaço resultante de uma construção social que, de acordo com Corezola, Oliveira e Almeida (2010), permite a integração, a articulação e a concertação entre os diversos atores sociais e políticas públicas, 
onde se dá a gestão social com vistas ao desenvolvimento territorial. Essa definição dialoga com a normativa disseminada no âmbito da política de desenvolvimento territorial.

Quando se trata de desenvolvimento territorial rural, Schejtman e Berdegué (2003) entendem que é preciso estimular e facilitar a interação e a articulação dos atores locais, entre si para que possam também se articular com os agentes externos relevantes. Portanto, pode-se afirmar que todo modelo de desenvolvimento que tenha a finalidade de impulsionar o desenvolvimento humano e elevar a qualidade de vida da população de um determinado território rural terá que levar em conta as realidades e potencialidades dos atores locais, a diversidade desses territórios e o perfil específico dos grupos formadores, como juventude, mulheres, povos e populações tradicionais.

A definição de uma política específica que tem como objeto de intervenção a concepção de território rural inicia-se em 2003, com a criação da Secretaria de Desenvolvimento Territorial (SDT) no âmbito do extinto Ministério do Desenvolvimento Agrário (MDA). O referencial disseminado pela política territorial do governo brasileiro é colocado em prática, no mesmo ano, pelo Programa Desenvolvimento Sustentável de Territórios Rurais (PRONAT), substituindo o "PRONAF Infraestrutura e Serviços Municipais", o qual atendia projetos de apoio ao desenvolvimento da agricultura familiar em escala municipal. Nesta mesma data, o Conselho Nacional de Desenvolvimento Rural e Agricultura Familiar (CONDRAF) publicou um texto de discussão que balizou a formulação de um programa de desenvolvimento sustentável de territórios rurais.

A criação do Programa foi justificada pela constatação de que as políticas de promoção do desenvolvimento rural no Brasil das últimas décadas foram "insuficientes", evidenciado pelo "aumento da pobreza e persistência das desigualdades regionais, setoriais, sociais e econômicas" (BRASIL, 2005b, p. 9), a política de apoio ao desenvolvimento sustentável de territórios rurais tem por objetivo "promover e apoiar iniciativas das institucionalidades representativas dos territórios rurais que objetivem o incremento sustentável dos níveis de qualidade de vida da população rural" (BRASIL, 2005b, p. 7).

Pensando numa estrutura capaz de captar as demandas da população e propor ações concretas para os gestores públicos, a SDT/MDA formatou os territórios da seguinte forma: Colegiados Territoriais, conduzidos por um núcleo dirigente chamado de coordenação executiva, que executa as deliberações das plenárias e por grupos temáticos que são as Câmaras e os Comitês Setoriais, que tratam de segmentos sociais específicos.

O Colegiado territorial é a principal instância de gestão dentro dos territórios rurais. Formado pelos verdadeiros atores colegiados com direito a voz e voto, e responsáveis pela participação e pela gestão social. Notadamente representa o principal instrumento de organização territorial. Delgado e Leite, (2011) se refere aos Colegiados Territoriais como "novas institucionalidades territoriais" os 
quais foram criados para diminuir as assimetrias históricas de poder na condução do desenvolvimento no meio rural brasileiro.

Para ampliar a ação do Plenário do Colegiado Territorial, o mesmo pode criar a aprovar Grupos Temáticos, que são espaços de inserção e participação para subsidiar suas decisões e deverão respeitar a diversidade de organização existente em cada realidade territorial. Onde essas instâncias já estejam constituídas no território, sem terem passado pelo Colegiado Territorial, a SDT/MDA recomenda que se dialogue com seus representantes e que se as reconheça como instâncias do Colegiado, garantindo sua representatividade nas demais instâncias, prevendo esta situação em regimento.

Esses espaços têm o papel de propor, dialogar e articular diferentes segmentos sociais, para que estejam devidamente engajados no processo e temas específicos relacionados ao desenvolvimento rural sustentável. Devem impulsionar a participação de setores historicamente excluídos dos processos decisórios (tais como mulheres, quilombolas, indígenas, jovens etc.) na estratégia de desenvolvimento rural com enfoque territorial.

Podem ter como integrantes representantes de organizações que não fazem parte do Plenário do Colegiado Territorial, mas que podem contribuir, substancialmente, com as discussões, articulações, estudos, pesquisas e ações em torno um determinado tema, setor ou segmento social e produtivo. Cada Câmara Temática e Comitê Setorial deve ter um caráter amplo, possibilitando a participação de quem se interessa pela questão: grupos autônomos, movimentos especificamente estruturados, organizações governamentais e não governamentais.

O Guia para Organização Social dos Territórios (2010), atribui as Câmaras Temáticas e aos Comitês Setoriais: Mobilizar, articular, organizar, discutir e encaminhar demandas de interesse de segmentos tradicionalmente excluídos das ações e políticas de desenvolvimento do território; aprofundar e ampliar discussões em torno de temáticas específicas e relevantes para o processo de desenvolvimento do território; favorecer articulações em rede com espaços afins; propor, acompanhar e monitorar projetos específicos para o território, bem como os critérios para seleção; propor critérios para a seleção e priorização de projetos específicos; propor e apoiar eventos e atividades de planejamento, formação e sistematização relacionadas aos temas que lhes são pertinentes, inclusive com recorte de identidade; definir seus objetivos, funcionamento e plano de trabalho, que devem ser apresentados ao Colegiado Territorial e custeados com recursos do território a presentar às instâncias do Colegiado Territorial os resultados de sua ação e sistematizar suas experiências.

A SDT/MDA recomenda que as Câmaras Temáticas e os Comitês Setoriais definam uma Coordenação, preferencialmente, formada por uma representação da sociedade civil e uma do poder público, com reconhecimento do Colegiado Territorial. Essa coordenação tem o papel de mobilizar, 
animar o processo de discussões, socializar informações e encaminhar recomendações e orientações ao Plenário do Colegiado Territorial.

Outras instâncias de caráter provisório, como Grupos de Trabalhos, Comissões, entre outras, poderão ser constituídas pelo próprio Plenário do Colegiado Territorial ou dentro das Câmaras Temáticas e dos Comitês Setoriais. Essas instâncias provisórias deverão ser organizadas com uma quantidade pequena de representantes, com o objetivo de executar uma tarefa específica, com prazo definido para sua conclusão. O Colegiado Territorial deve ter claro o objetivo dessas instâncias provisórias e realizar o planejamento da tarefa demandada.

\section{Metodologia}

A concepção que orienta as discussões neste artigo considera o funcionamento dos grupos temáticos, por meio dos atores sociais locais, fundamentais na gestão participativa do território, de tal forma que esses grupos temáticos ativos consistem em um trabalho fundado em uma relação dialógica e crítica entre os sujeitos envolvidos no processo de desenvolvimento territorial. Embora o conhecimento científico possa contribuir de maneira importante para esse desenvolvimento, somente alcançará este objetivo, se estiver em constante diálogo com os gestores sociais e com a experiência de suas organizações. Trata-se de um processo de construção conjunta, que reconhece a possibilidade das relações entre o seu ideário e as consequências práticas de sua atuação. Entender os grupos temáticos a partir desta perspectiva é uma formar de contribuir para a formação do referencial científico do Território Piemonte da Borborema.

O estudo foi realizado no Território Rural Piemonte da Borborema/PB. Foi priorizada a pesquisa qualitativa, que tem como uma de suas características a orientação para o processo e não para o resultado, com ênfase no entendimento e não exatamente num objetivo pré-determinado (CASSELL; SYMON, 1994).

A abordagem qualitativa foi de caráter descritivo e exploratório. De acordo com Triviños (1987) nesse tipo de estudo o pesquisador tem como propósito aumentar sua experiência em torno de um determinado problema, associado ao levantamento bibliográfico foi utilizada a técnica de investigação feita a partir da coleta de dados secundários.

Os dados secundários foram do banco de dados do Instituto Brasileiro de Geografia e Estatística (IBGE), de relatórios de estudos produzidos sobre o Território Rural Piemonte da Borborema/PB, documentos do próprio Território, informativos publicados, regimento interno, relatórios e análise das diretrizes gerais.

\section{Resultados e Discussão}


O Território Rural Piemonte da Borborema foi homologado em 2010 durante a realização do "I Salão dos Territórios da Paraíba". Os oito novos territórios homologados foram integrados aos homologados anteriormente, perfazendo um total de 15 Territórios Rurais no Estado. Mas o reconhecimento da importância da política de desenvolvimento territorial na Paraíba pelo CONDRAF só ocorreu em 23 de maio de 2013, por meio da Resolução No 94, que incorporou o Território Rural Piemonte da Borborema, entre outros, ao PRONAT (PEREIRA FILHO, 2016).

Figura 1 - Municípios do Território Piemonte da Borborema, Paraíba.

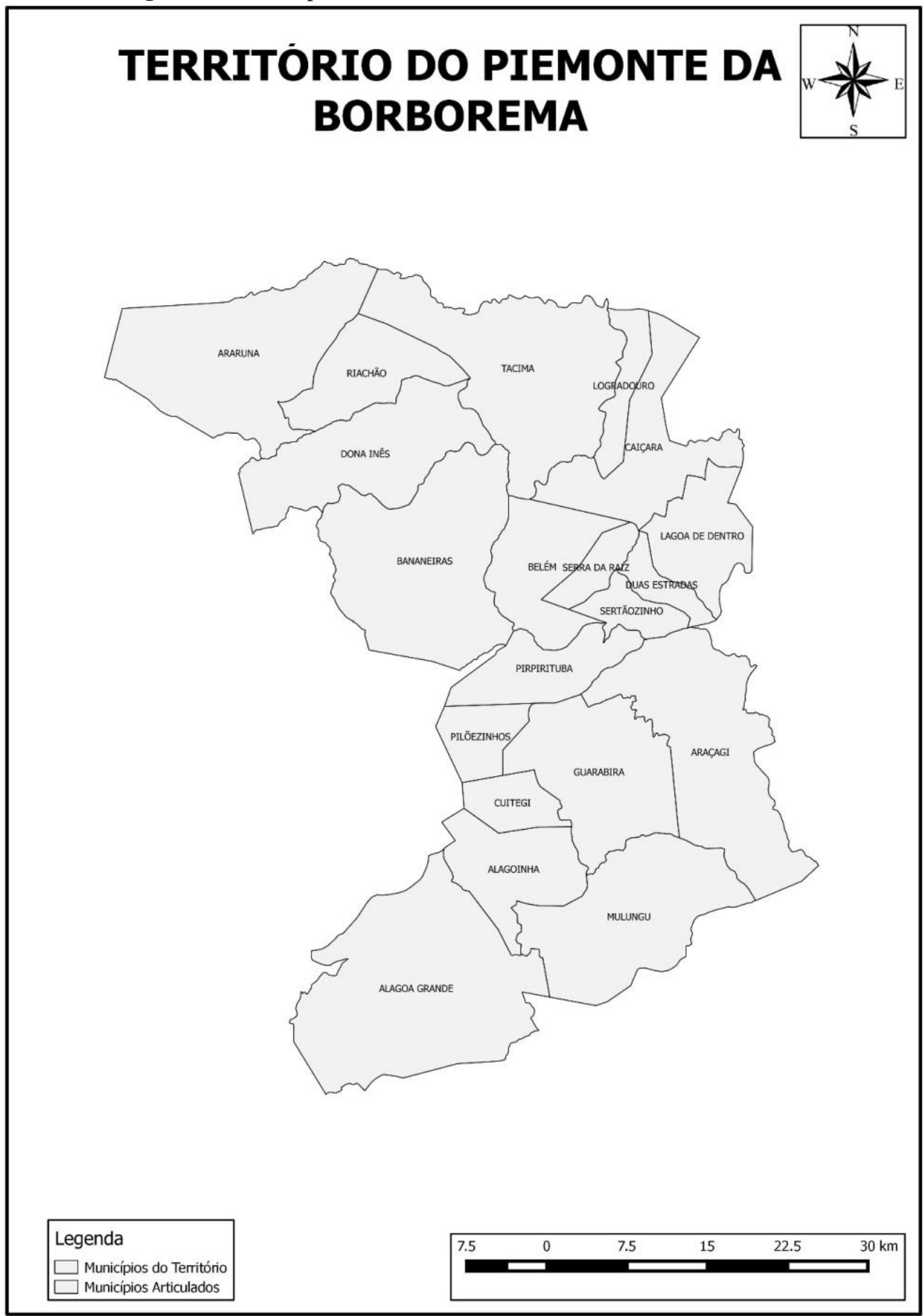

Fonte: Fonte Própria. 
O Território Rural Piemonte da Borborema - PB, localizado na região Nordeste, é composto por 20 municípios: Alagoa Grande, Alagoinha, Araçagi, Araruna, Bananeiras, Belém, Caiçara, Cuitegi, Dona Inês, Duas Estradas, Guarabira, Lagoa de Dentro, Logradouro, Mulungu, Pilõezinhos, Pirpirituba, Riachão, Serra da Raiz, Sertãozinho e Tacima, conforme a figura 1.

Esse Território possui uma área de 2.649,40 km², uma população total de 258.081 habitantes, sendo $165.348(64,07 \%)$ de população urbana, e $92.733(35,93 \%)$ de população rural. As especificidades em relação à população do território são aproximadamente 112 pescadores; 17.421 estabelecimentos da agricultura familiar; 1.989 famílias assentadas; 86.679 beneficiários do programa bolsa família, duas comunidades de remanescentes de quilombolas localizadas no município de Dona Inês e Alagoa Grande (CENSO DEMOGRÁFICO 2010A E IBGE CIDADES).

Observa-se o quanto o Território Rural Piemonte da Borborema é grande e diversificado ambiental, cultural e socialmente. Esse panorama revela a necessidade de pensar ações estratégicas para que o desenvolvimento territorial realmente ocorra em todo o Território e não sejam privilegiados de grupos ou municípios. O trabalho desenvolvido no do Território ganha nova perspectiva quando a preocupação é valorizar os mais diversos atores sociais e fazê-los se encontrarem dentro do seu território, um local de disputa de poder, mas também de conquistas.

Ciente dessa diversidade territorial, a Resolução N 52 De 16 de fevereiro de 2005 do Conselho Nacional de Desenvolvimento Rural Sustentável - CONDRAF traz no seu Artigo $4^{\circ}$ que a institucionalidade territorial deverá ser composta em função dos atores presentes no território de forma a contemplar as questões de gênero, raça, etnia e geração na sua composição; levar em conta os princípios da representatividade, diversidade e pluralidade dos atores e estar aberta para a inclusão de novos atores.

Apesar de o Plenário do Colegiado Territorial ser a instância máxima, esta não é suficientemente capaz de suportar a demanda oriunda de grupos de atores específicos do território. $\mathrm{O}$ Plenário fica em falta com o Colegiado por duas razões. Primeiro, o Plenário tem sua dinâmica própria, se reunindo no máximo três vezes por ano para discutir questões gerais do interesse de todo o Colegiado. Segundo, para discutir questões específicas é necessário um olhar especializado e objetivo, sendo imprescindível que as demandas sejam trabalhadas separadamente.

Reconhecendo essa necessidade e o que predispõe o Artigo $1^{\text {a }}$ do Regimento Interno do Fórum de Desenvolvimento Territorial Sustentável do Piemonte da Borborema, o Colegiado Territorial criou em 2016 quatro grupos temáticos de acordo com a determinação do Artigo $7^{\circ}$ do Regimento Interno. Na primeira reunião do Colegiado Territorial, realizada no mês de abril, o Plenário aprovou a criação do Comitê de Povos e Populações Tradicionais, do Comitê de Gênero e da Câmara de Inclusão 
Produtiva. Na segunda reunião do Colegiado Territorial, realizada no mês de agosto, o Plenário aprovou a criação do Comitê de Juventude Rural.

Após sua criação esses grupos temáticos, Comitês Setoriais e Câmara, vêm se reunindo mensalmente para promover a integração e o debate de temas específicos, que por sua vez são definidos a partir de questões relevantes e das demandas e necessidades dos próprios beneficiários, de sorte a contribuir com o desenvolvimento territorial.

Como forma de contribuir para o desenvolvimento territorial, o PRONAT começou a repassar recursos de projetos municipais para projetos territoriais a partir da criação do Programa de Apoio a Projetos de Infraestrutura e Serviço em Territórios Rurais (PROINF) para apoiar agricultores (as) familiares, quilombolas, pescadores, comunidades ribeirinhas e indígenas. Destacamos aqui apenas PROINFs dos nos de 2015 e 2016, lançados para os territórios do Brasil.

O PROINF 2015 foi de Apoio a Infraestrutura em Territórios Rurais e teve como objetivo Viabilizar a estruturação e/ou qualificação de serviços públicos locais, territoriais ou estaduais para a produção, armazenamento, transporte, comercialização e inspeção sanitária de produtos da agricultura familiar de municípios localizados nesses territórios. O recurso inicial disponível foi de $\mathrm{R} \$ 250.000,00$ por território. Entretanto havia um valor adicional por Comitê existente: Comitê de Mulheres R\$ 50.000,00; Comitê de Jovens R\$ 50.000,00; Comitê de Povos e Comunidades Tradicionais R\$ 50.000,00; totalizando um valor de R\$ 400.000,00. No ano de 2015 o Território Piemonte da Borborema não tinha esses Grupos Temáticos constituídos e concorreu ao edital do PROINF apenas com o valor inicial sem nenhum adicional.

No ano de 2016 surgiram os chamados PROINFs Chamadas Especiais. Houve a Chamada Especial para Grupos Produtivos de Mulheres e Chamada Especial para Juventude Rural. A Chamada Especial para Grupos Produtivos de Mulheres teve o objetivo de viabilizar infraestrutura rural para estruturação produtiva, beneficiamento, equipamentos para processamento de produtos agropecuários, transporte e armazenamento da produção de grupos produtivos de mulheres rurais oferecendo mecanismos de agregação de renda. Os recursos disponíveis na proposta eram sob o valor de $\mathrm{R} \$ 100.000,00$ que poderia ser ampliado em 20\% caso no Comitê de Mulheres fosse comprovada a participação de jovens e/ou representação de Povos e Comunidades Tradicionais na sua composição, alcançando o valor máximo de repasse de $\mathrm{R} \$ 120.000,00$.

A Chamada Especial para Juventude Rural foi de financiamento exclusivo de infraestrutura para o funcionamento de Escolas Famílias Agrícolas, Escolas Comunitárias Rurais e Casas Familiares Rurais nos Territórios, com o orçamento da Ação de Apoio a Infraestrutura e Serviços aos territórios com Comitês Territoriais de Juventude. Para cada Território seria empenhada apenas uma proposta sob o valor de $\mathrm{R} \$ 100.000,00$ que poderia ser ampliado em 20\% caso o Comitê de Juventude 
comprovasse o registro de representação de mulheres e/ou de povos e comunidades tradicionais na composição, alcançando o valor máximo de repasse de $\mathrm{R} \$ 120.000,00$.

É possível perceber a importância dos grupos temáticos como estratégias de desenvolvimento territorial seja a partir do aprofundamento da discussão de temas específicos para os grupos identitários e estratégicos para o desenvolvimento territorial, ou seja pela formulação de programas e projetos específicos a partir da discussão técnica e política.

Embora as discussões e formações ocorram de forma isolada nesses grupos temáticos, é de grande relevância o efeito sobre diversos atores, que apesar de terem demandas diferenciadas, suas necessidades perpassam o isolamento e os colocam no mesmo grupo. Paradoxalmente os grupos temáticos separam pela terminologia, Comitê de Gênero, Comitê de Povos e Populações Tradicionais, Comitê de Juventude, e aglutina pela necessidade de fortalecimento da discussão política e da formação da identidade territorial, quando se percebe quilombolas e jovens participando do Comitê de Mulheres e vice-versa.

Os Comitês e a Câmara formados recentemente no Território Piemonte da Borborema não contribuíram para valores adicionais nos projetos PROINFs devido o pouco tempo de formação. Entretanto, nesse pouco tempo de formação foram realizadas reuniões de formação política, empoderamento dos sujeitos, participação de encontros em outros territórios, formação e redescobrimento da identidade territorial bem como fortalecimentos das relações interpessoais.

Essa formação de base que vem sendo realizada em todos os Grupos Temáticos do Território corresponde aos anseios dos mesmos, diante da enorme necessidade de aprofundamento de alguns temas de extrema importância para o Território Piemonte da Borborema. Discutir igualdade de gênero, por exemplo, mostrou o quanto essa pauta estava esquecida pela discussão territorial. No Comitê de Gênero as participantes têm demandado e discutido também o papel da mulher na política, direitos da mulher, conjuntura política atual do país, direitos LGBTs e organicidade do Comitê.

O Comitê de Mulheres do Piemonte da Borborema juntamente com os comitês de outros territórios da Paraíba realizaram o Seminário Multiterritorial de Políticas Públicas para Mulheres Autonomia, poder e participação, durante dois dias do mês de julho na cidade de Cuité, Território da Borborema, além desses dois, estiveram presentes os Territórios: Alto Sertão, Médio Sertão, Médio Piranhas, Cariri Oriental, Cariri Ocidental, Curimataú, Seridó, Serra do Teixeira, Vale do Paraíba, Vale do Piancó, Vale do Piranhas, Zona da Mata Norte e Zona da Mata Sul. O objetivo específico do Seminário foi unificar, entre as mulheres dos territórios da Paraíba, o conhecimento sobre políticas públicas e visando o reconhecimento da mulher como protagonista do processo de emancipação e autonomia. Como encaminhamento principal do Seminário foi a criação do Fórum Estadual de Políticas Públicas para Mulher. 
O Comitê de Povos e Populações Tradicionais é formado por duas comunidades Quilombolas, Caiana dos Crioulos, cidade de Alagoa grande, e Cruz da Menina, cidade de Dona Inês. Comunidades vivendo o processo demarcatório em etapas diferentes. O conhecimento da realidade dessas duas comunidades revelam também diferenças organizacionais e culturais. Logo, o trabalho quem vem sendo realizado são diferentes e voltados para suas necessidades mais importantes. No Quilombo Cruz da Menina a discussão tem sido voltada mais para a questão da sua própria terra, o seu território de vivência. Foram realizadas oficinas de cartografia social, uma maneira de mapear o território quilombola de forma participativa, e de resgate histórico e cultural da comunidade. Já no Quilombo Caiana dos Crioulos, a discussão realizada, de acordo com a demanda da comunidade, foi a da banda de pífano. Dessa forma, os músicos estão tendo oficinas com aulas de teoria musical, de grafia musical (partituras), de percepção rítmica e melódica.

Entre as expressões culturais da comunidade, a banda de pífano se destaca pelo desgaste que sofreu nos últimos anos em decorrência da perda de seus tocadores. As oficinas estão tendo o importante papel de instrumentalizar musicalmente e canalizar a vocação já existente naqueles que estão se descobrindo músicos, tocadores de pífano. A continuidade da banda de pífano simboliza para o quilombo Caiana dos Crioulos a força cultural de seu povo, importante fator de reconhecimento e fortalecimento da sua cultura e de sua vivência prática.

As reuniões, formações e oficinas do Comitê de Povos e Populações Tradicionais, principalmente os comitês de outros territórios, levaram à percepção da criação do Fórum Estadual de Comunidades Quilombolas. O Fórum está em processo de oficialização e será um espaço para reunir de forma participativa o poder público e a sociedade civil, a fim de proporcionar uma melhor qualificação das ações direcionadas para solucionar ou minimizar os problemas decorrentes deles.

\section{Conclusões}

Os Grupos Temáticos, Câmara Temática e Comitês Setoriais, do Território Piemonte da Borborema mantêm um ritmo acelerado de encontros de formação a atuação dentro do Território. Nessas reuniões os grupos identitários reúnem o poder público e a sociedade civil para fortalecer e ampliar a participação social através da discussão dos possíveis gargalos que afetam bem como as soluções viáveis para avanços.

O Comitê de Gênero, Comitê de Povos e Populações Tradicionais, Comitê de Juventude Rural e Câmara de Inclusão Produtiva vem favorecendo a dinâmica do desenvolvimento territorial a partir do empoderamento político e cultural dos sujeitos pertencentes a estes grupos específicos.

\section{Referências}


BRASIL. Conselho Nacional de Desenvolvimento Rural Sustentável - CONDRAF: RESOLUÇÃO Nº 52 DE 16 DE FEVEREIRO DE 2015. Brasília: SDT/MDA.

BRASIL. Ministério do Desenvolvimento Agrário. Secretaria de Desenvolvimento Territorial. Marco referencial de apoio ao desenvolvimento de territórios rurais. Brasília: SDT/MDA, 2005a.

Referências para uma estratégia de desenvolvimento rural sustentável no Brasil. Brasília: SDT/MDA, 2005b. (Série Documentos SDT, n.1).

CASSELL, C.; SYMON, G. Qualitative methods in organizational research. London: Sage Publications, 1994.

COREZOLA, F.; OLIVEIRA, C. D.; ALMEIDA, M. G. Desafios da Governança Territorial nos Territórios Incorporados ao Programa Territórios da Cidadania. Campina Grande, PB, Revista Raízes. v. 28, p. $87-96,2010$.

CRESWELL, John W. Projeto de pesquisa: métodos qualitativo, quantitativo e misto. Tradução de Luciana de Oliveira da Rocha. 2. ed. - Porto Alegre: Artmed, 2007. 248 p.

DELGADO, N. G.; LEITE, S. P. Gestão Social e Novas Institucionalidades no Âmbito da Política de Desenvolvimento Territorial. In: Políticas Públicas, Atores Sociais e Desenvolvimento Territorial no Brasil. Brasília: IICA. Série Desenvolvimento Rural Sustentável, v. 14, 2011. p. 89-130.

GEHLEN, Ivaldo. Políticas públicas e desenvolvimento social rural. São Paulo: São Paulo em Perspectiva. v.18(2), n.2, abr-jun, 2004. p. 95-103. Disponível em: <www.scielo.br/pdf/spp/v18n2/a10v18n2.pdf>. Acesso em: 28 set. 2016.

IBGE - Instituto Brasileiro de Geografia e Estatística. Censo Demográfico 2010a. Disponível em: http://www.ibge.gov.br. Acesso em: 28 de set. de 2016.

PEREIRA FILHO, T. B.; PEREIRA, P. S.; MARQUES, A. C. N. Núcleo De Extensão em Desenvolvimento Territorial (NEDET): Território Rural Piemonte da Borborema. In: XXIII Encontro Nacional de Geografia Agrária, 2016, São Cristóvão - SE. Anais do Encontro Nacional de Geografia Agrária, 2016.

SCHEJTMAN, Alexander y BERDEGUÉ, Julio A. Desarrollo territorial rural. Centro Latino Americano para o Desarrollo Rural, 2003, 54 p. Caderno Debates y Temas Rurales. n. 1. Disponível em: <www.rimisp.org>. Acesso em: 28 set. 2016.

TRIVIÑOS, A. Introdução à pesquisa em ciências sociais: a pesquisa qualitativa em educação. São Paulo: Atlas, 1987.

VEIGA, José Eli. Desenvolvimento rural: o Brasil precisa de um projeto. Anais do $36^{\circ}$ Congresso Brasileiro de Economia e Sociologia Rural (SOBER), Poços de Caldas, MG, vol. 1, pp. 153-186, 1998. 